\title{
Quantifying The Hidden Healthcare Cost Of Diabetes Mellitus In Australian Hospital Patients
}

Karahalios Amalia, $\mathrm{PhD}^{1,2^{*}}$, Somarajah Gowri, MB BS ${ }^{3}$, Hamblin Peter S, MB BS(Hons) FRACP ${ }^{4,6}$, Karunajeewa Harin, PhD $^{1,3,5}$, Janus Edward D, PhD ${ }^{1,3,6}$

${ }^{1}$ Western Centre for Health Research and Education, Western Health, St Albans, VIC, Australia

${ }^{2}$ Centre for Epidemiology and Biostatistics, Melbourne School of Population and Global Health, University of Melbourne, Melbourne, VIC, Australia

${ }^{3}$ General Internal Medicine Unit, Western Health, Sunshine Hospital, St Albans, VIC, Australia

${ }^{4}$ Endocrinology and Diabetes Unit, Western Health, St Albans, VIC, Australia

${ }^{5}$ The Walter and Eliza Hall Institute of Medical Research, Parkville, VIC, Australia

${ }^{6}$ Department of Medicine, Melbourne Medical School - Western Precinct, The University of Melbourne, St Albans, Vic, Australia, 3021

${ }^{*}$ Corresponding author:

Amalia Karahalios, $\mathrm{PhD}$

Level 3, 207 Bouverie Street

The University of Melbourne, Victoria 3010 Australia

T: +613 83443835

E: emily.karahalios@unimelb.edu.au

Word count:

Abstract $=250$ words

Main text $=2,489$ words

This is the author manuscript accepted for publication and has undergone full peer review but has not been through the copyediting, typesetting, pagination and proofreading process, which may lead to differences between this version and the Version of Record. Please cite this article as doi: $10.1111 / \mathrm{imj} .13685$

This article is protected by copyright. All rights reserved. 


\section{Acknowledgements}

We thank Manmeet Singh and Sean Downer from Western Health's Health Performance Unity for assistance in data extraction, and Graham Bushnell from the Clinical Costing Unit for the clinical costing data used in this study.

We thank Emily Callander (Australian Institute of Tropical Health and Medicine, James Cook University, Townsville, Australia) for helpful comments on this manuscript.

HK is supported by an Australian National Health and Medical Research Council Career Development Fellowship. 
Background: Diabetes mellitus in hospital inpatients is most commonly present as a comorbidity rather than as the primary diagnosis. In some hospitals, the prevalence of comorbid diabetes mellitus across all inpatients exceeds $30 \%$, which could add to complexity of care and resource utilization. However, whether and to what extent co-morbid diabetes mellitus contributes indirectly to greater hospitalization costs is ill-defined.

Aim: This study determined the attributable effect of co-morbid diabetes mellitus on hospital resource utilisation in a General Internal Medical service in Melbourne, Australia.

Methods: We extracted data from a database of all General Internal Medical discharge episodes from July 2012-June 2013. We fitted multivariable regression models to compare patients with diabetes mellitus to those without diabetes mellitus with respect to hospitalisation cost, length of stay, admissions per-year and inpatient mortality.

Results: Of 4,657 patients $1,519(33 \%)$ had diabetes mellitus, for whom average hospitalisation cost (AUD9,910) was higher than those without diabetes mellitus (AUD7,805). In multivariable analysis this corresponded to a 1.22 -fold $(95 \% \mathrm{Cl}: 1.12-1.33, \mathrm{p}<0.001)$ higher cost. Mean length of stay for those with diabetes was 8.2 days versus 6.8 days for those without diabetes, with an adjusted 1.19-fold greater odds $(95 \% \mathrm{Cl}: 1.06-1.33 ; \mathrm{p}=$ 0.001 ) of staying an additional day. Number of admissions and mortality were similar.

Conclusion: Co-morbid diabetes mellitus adds significantly to hospitalisation duration and costs in medical inpatients. Moreover, diabetes mellitus patients with chronic complications had a greater-still cost and hospitalisation duration compared to those without diabetes mellitus.

Keywords: health care use, costs, adult diabetes mellitus 


\section{Introduction}

In 2011-2012, approximately 1 million Australians were diagnosed with diabetes mellitus (DM)

${ }^{1}$. In 2008-2009 it was estimated that total health sector expenditure for DM was AUD1,507 million ( $2.3 \%$ of Australia's total health-expenditure); of which, in-hospital costs accounted for roughly $43 \%$ (AUD647 million) ${ }^{2}$ and represent the major driver of the current trajectory of increasing healthcare costs from DM over recent years ${ }^{2,3}$. However, existing estimates of DM-related hospital costs have been derived from hospital data from patients admitted with DM as a primary diagnosis, and do not account for more indirect effects on health costs that might result from DM being present as a co-morbidity. A recent study demonstrated that in Melbourne, overall DM prevalence in hospital inpatients was as high as $35 \%{ }^{4}$. However, in only a relatively small proportion of these was the admission primarily attributed to DM. Therefore, DM in hospital inpatients is most commonly present as a co-morbidity rather than as the defined primary diagnosis. Existing Australian cost of illness studies may have significantly underestimated the real costs associated with inpatient care for DM.

We hypothesised that in Australian hospitals, co-morbid DM may add to health service utilisation and costs in broader and more indirect ways than previously appreciated, including in patients admitted for a range of conditions that may not necessarily be directly related to their DM. We undertook a study to quantify the added health service utilisation and costs attributable to DM (regardless of reason for admission) in a predominantly elderly, multimorbid population representative of Australia's modern hospital population. 


\section{Methods}

\section{Population}

The study was conducted at Western Health, a tertiary-level health service with three major hospital campuses in Melbourne, Australia.

\section{Data source}

A database at Western Health records patient age, sex, marital/spousal status, language spoken at home and detailed ICD-10 coding information, including a single assigned "primary diagnosis" and all co-morbidities ascribed to that patient during the admission. Inpatient length of stay (LOS), calculated in days from admission until discharge from the health service, is recorded, as are data on per-patient health service financial expenditure for each admission. These data are derived from a clinical costing algorithm routinely applied to all admission episodes with all costs summed to derive an individual clinical costing (ICC) that represents the total financial expenditure by the health service for each individual patient admission episode.

\section{Inclusion and exclusion criteria}

Data were extracted from all 5,944 discharge episodes from a total of 4657 patients on the General Internal Medical (GIM) service between 1 July 2012 and 30 June 2013. These included 847 patients who had more than one admission (590 patients had two and 257 patients had three or more admissions) within the 12-month study period. Because we were primarily interested in total per-patient (rather than per-admission) health service utilisation, repeated admissions occurring in the same patient were aggregated to a single record for each patient (see below for further details).

\section{Exposures of interest}

The main exposure variable of interest was DM; a dichotomous variable created based on whether or not the patient had ever had any DM-related ICD-10 diagnostic code defined at 
any admission during the study period. Each patient's complete list of ICD-10 codes was also mapped to each of the co-morbidity groupings that constitute the Charlson's Co-morbidity Index $(\mathrm{CCl})^{5-9}$. This enabled us to define a $\mathrm{CCl}$ score for each patient, with modification according to the presence of DM as described below. Routine ICD-10 coding procedures also enable differentiation of DM with chronic complications from DM without chronic complications (see appendix for further details) ${ }^{5,9-11}$.

\section{Confounding variables}

To control for potentially confounding factors we, a priori, selected variables that could plausibly impact on the association between presence of DM and the outcomes defined below. In addition to age, sex and smoking status (dichotomized as ever or never smoker), we included spousal support, dichotomised into: "spousal support" (married or de facto) or "no spousal support" (single, widowed, divorced or separated) as a surrogate of carer support at home. As well, in our population, with high proportions of non-English speaking migrants, complexities in delivering care (e.g. need for interpreter services) can contribute to treatment delays and added costs, therefore we included language status (English versus another language spoken at home).

\section{Outcomes}

We pre-specified the following four outcomes of interest for each patient: ICC, LOS, the number of recurrent admissions (occurring in the same patient during the 12 month study period), and in hospital mortality. The primary outcome variable, ICC, represents the total sum of direct patient costs and overheads measured in Australian dollars (AUD) in 2012-2013. Further details of how the outcomes were derived can be found in the Appendix.

\section{Statistical methods}

We fitted univariable and multivariable models to estimate the association between the patient ever having DM and ICC, LOS, number of admissions and mortality. For ICC, we fitted generalized linear regression models, with a gamma error distribution and log link ${ }^{12-14}$; for 
LOS, we fitted ordinal logistic regression models; for the number of admissions we fitted Poisson regression models; and for mortality we used logistic regression.

Despite the skewed nature of LOS and ICC data, mean values are often preferred indicators of overall organisational expenditure. We estimated mean LOS and ICC, and the corresponding $95 \%$ confidence intervals $(95 \%$ Cls) using non-parametric bootstrap sampling

${ }^{15}$. Three thousand samples were taken for each confidence interval and bias corrected and accelerated confidence intervals are presented ${ }^{13,15}$.

All analyses were done using Stata version $13 \cdot 1^{16}$.

\section{Ethical approval}

The study was approved by the Western Health Human Research and Ethics Committee (Approval no. QA 2014.24).

\section{Results}

Of 4,657 patients with complete data who were discharged from the GIM service between 1 July 2012 and 30 June 2013, 2,472 were female (53\%), median age was 76 years (interquartile range $(\mathrm{IQR})=62,84), 283(6 \%)$ died in hospital, and 1,519 $(33 \%)$ had DM. Table 1 shows the characteristics of the patients by presence or absence of DM. There were similar proportions of males/females, spousal support and ever smokers/never smokers, and a similar median age in both groups. However, the proportion of patients aged 60 to 80 years was higher for those with DM $(n=781 ; 51 \%)$ than those without DM $(n=1,073 ; 34 \%)$. As expected, patients presenting with DM had a higher $\mathrm{CCl}($ median $=3, \mathrm{IQR}=2,5)$ compared to those without DM (median $=1, I Q R=0,2$ ). However, the modified CCI Index, which excluded DM as a comorbidity, was similar between those with $D M($ median $=1, I Q R=0,3$ ) and those without DM (median $=1, I Q R=0,2)($ Table 1$)$.

Insert table 1 here 


\section{Individual clinical costs (ICC)}

After aggregating for multiple stays, unadjusted average (95\% CI) ICC per-patient with DM was AUD9,910 $(9,199-10,622)$ and for those without DM it was AUD7,805 $(7,470-8,141)$. Of the total costs for patients with DM $74 \%$ were attributed to direct hospital costs (medical, nursing and allied health wages, ward consumables, theatre costs, drugs, anaesthetics, pathology and imaging) and $26 \%$ to "hospital overheads" (utilities, cleaning, medical records, finance, administration, security, information technology and engineering). The proportion was the same for those without DM. The majority of direct costs in both diabetic and non-diabetic admissions related to medical and nursing wages. These and "hospital overheads" were likely to primarily reflect length of hospital stay. For patients with DM with chronic complications the average ICC was AUD11,426 (10,49512,358), compared to those with DM without chronic complications AUD7,225 $(95 \% \mathrm{Cl}=$ $6,200-8,249)$. Patients with DM had a 1.22-fold increased relative ICC compared to those without DM $(95 \% \mathrm{Cl}=1.12-1.33, \mathrm{p}$-value < 0.001) (Table 2). Further, patients with DM with chronic complications had a 1.40-fold increased relative ICC compared to those without DM $(95 \% \mathrm{Cl}=1.28-1.53, \mathrm{p}$-value $<0.001)$

Insert table 2 here

\section{Length of stay}

After aggregating for multiple stays, average total LOS during the study period was 8.2 days $(95 \% \mathrm{Cl}=7.7-8.8)$ in patients with $\mathrm{DM}$ and 6.8 days $(95 \% \mathrm{Cl}=6.5-7.1)$ in patients without DM. The LOS was longer for patients with DM with chronic complications $(9.5 ; 95 \% \mathrm{Cl}=8.8$ - 10.2 days) compared to those with DM without chronic complications $(6.0 ; 95 \% \mathrm{Cl}=5.1$ 6.9 days). Comparing patients with DM to those without, the odds were 1.19-fold greater $(95 \% \mathrm{Cl}=1.06-1.33, \mathrm{p}$-value $=0.002)$ for staying an additional day, given the other variables were held constant in the model (Table 2). Further, patients with DM with chronic complications compared to those without chronic complications had a 1.56 -increased odds $(95 \% \mathrm{Cl}=1.37-1.78, \mathrm{p}$-value $<0.001)$ of staying an additional day (Table 2$)$. 


\section{Number of admissions, mortality}

The average total number of per-patient admissions for patients with DM with chronic complications $(1.48 ; 95 \% \mathrm{Cl}=1.42-1.54$ admissions $)$ was higher than for patients without chronic complications $(1.16 ; 95 \% \mathrm{Cl}=1.12-1.20$ admissions). After adjusting for the potential confounding variables mentioned above, the total number of admissions was similar between patients with and without $\mathrm{DM}(\mathrm{RR}=1.07,95 \% \mathrm{Cl}=1.01-1.13, \mathrm{p}=0.022)$. However, patients with DM with chronic complications had a greater number of admissions $(R R=1.15 ; 95 \% \mathrm{Cl}=1.08-1.23, p$-value $<0.001)$ compared to those without DM (Table 3). In hospital mortality was similar between patients with and without $\mathrm{DM}(\mathrm{OR}=1.00,95 \% \mathrm{Cl}=$ $0.79-1.28, p$-value $=0.974)($ Table 3$)$. However, patients with DM with chronic complications had higher, although not statistically significant, odds of death $(\mathrm{OR}=1.27 ; 95 \% \mathrm{Cl}=0.98$ $1.65, \mathrm{p}$-value $=0.074)$ than those without DM.

Insert table 3 here 


\section{Discussion}

Our study highlights the high indirect attributable burden of DM on hospitalisation costs.

Although limited to a sub-group of non-surgical, non-obstetric hospitalised adults, the $33 \%$ DM prevalence in GIM patients accorded well with previously documented DM prevalence throughout our entire Health Service ${ }^{4}$. We found that, following adjustment for confounders, patients with co-morbid DM had a 1.22-fold higher ICC and 1.19 fold odds of staying longer in hospital. However, number of admissions and mortality risk were similar between the two groups. Moreover, DM patients with chronic complications had a greater-still ICC $(R R=1.40)$, a longer stay in hospital $(R R=1.56)$, more admissions $(R R=1.15)$ and a slightly increased odds of in hospital mortality $(O R=1.27)$ compared to those without DM.

A number of studies have demonstrated the high societal and medical costs of DM from a community perspective ${ }^{17-19}$. However there exist few studies that have specifically quantified hospital costs in patients with and without diabetes ${ }^{20,21}$. Furthermore, previous reports within Australia have looked at the average per-separation cost for people admitted with a primary diagnosis related directly to DM. However our study looked at all patients with DM, not just those admitted due to DM as primary diagnosis. This is reflected in the higher per-patient cost reported in this study (AUD 9,910), compared to previous studies (AUD 8,368 in 2012 dollars (extrapolated from 2008 data) $)^{2}$. For our institution, with a catchment population of 650,000 ( $1.5 \%$ of the Australian population), the additional annual cost for $1500 \mathrm{GIM}$ patients at AUD 2000 each is AUD $3,000,000^{2}$. The cost implications for our own health service and for the whole of Australia are clearly very large.

Strengths of our study included use of an ICC metric of cost representing a direct measurement of health system expenditure for each individual patient, rather than a modelbased estimation of costs that is often employed in health care cost studies. Our methods also enabled us to control for potential confounding variables. However we acknowledge that the retrospective design may have failed to account for other potential confounders not present in our dataset. 
Two possible major factors might underlie our findings of higher ICC and LOS in our patients with DM. Firstly, it might reflect pathophysiological factors: DM could potentiate the risk of nosocomial (such as hospital-acquired infection) and other complications more likely in people with diabetes. Our finding that DM with chronic complications was associated with even greater increased ICC and longer LOS than DM without chronic complications might be consistent with this. Secondly, it might reflect organizational/system issues, contributing especially to the longer LOS in DM. It seems likely that both factors are at play, however dissecting the relative contributions of each is beyond the scope of this study.

Our study had a large sample size but was limited to a single Australian health service with only three hospitals. The demographic characteristics of the catchment population are broadly similar to the Australian population but are characterised by relative social disadvantage and the highest population prevalence of diagnosed DM in the country (up to $6.6 \%$ compared to the Australian national prevalence of $4.9 \%)^{22}$. As well, the demographic characteristics of the participants with diabetes mellitus is similar to the characteristics of the Australian population with diabetes mellitus ${ }^{1}$. The three hospitals in our study appear to be similar to hospitals across Australia. The top five principal diagnosis codes for our population (I50, J18, J44, L03, 121) ranked as the $6^{\text {th }}, 1^{\text {st }}, 2^{\text {nd }}, 4^{\text {th }}$, and $5^{\text {th }}$ most common non-obstetric, non-surgical hospital codes in the AlHW hospital admissions dataset

(https://www.aihw.gov.au/reports/hospitals/australian-refined-diagnosis-related-groups-ardr/contents/data-cubes, accessed 2 October 2017). Approximately $25 \%$ of all non-obstetric, non-surgical adult inpatient admissions to Western Health are cared for by our GIM service a proportion similar to much hospital practice throughout Australia. Our population is therefore representative of a significant proportion of the hospitalised population of Australia. However we acknowledge that our data failed to capture a broader range of admission episodes, especially in patients admitted for surgical conditions or cared for by medical sub-specialty units (such as cardiology, nephrology etc.). It is not clear whether and to what extent our findings might apply in these settings. It is also possible that some of the patients in our study may also have been admitted to other hospital units within the duration of our study thus incurring further costs. GIM patients are predominantly elderly, have high rates 
of multiple comorbidities and are admitted for a range of primary diagnoses, the most common of which include community-acquired respiratory infection (including pneumonia), exacerbations of chronic lung disease, acute congestive cardiac failure and cellulitis. Undifferentiated presentations and admissions for social reasons or end-of-life care are also common. It therefore might have been subject to unique factors present at our organisation. However we hypothesise that the contributory factors may be ubiquitous throughout the health system.

Additional limitations included the lack of data regarding other potential confounders such as prescription and overall drug use ${ }^{23}$. Our data were also subject to the accuracy of coding of the diagnosis of DM in the clinical record and therefore there is the potential for differential misclassification bias ${ }^{24}$. This could affect not only our definitions of patients with diabetes versus those without but also our discrimination between those with "uncomplicated diabetes" versus "diabetes with chronic complications". Indeed recent studies in our setting have shown that this approach may underestimate the real prevalence of diabetic complications (that approaches $80 \%$ when determined by a carefully structured interview). Therefore our comparisons between these two groups should be interpreted cautiously ${ }^{4}$.

Our study was limited to an analysis of direct hospital costs and should therefore be considered a health cost study, rather than a health economic study per se. Analysis of indirect health costs (including effects of illness on income and productivity) were not incorporated and we therefore have not addressed broader economic effects of diabetes at a societal level in this study.

Our study effectively assigns an "attributable fraction" or "proportion" of excess costs of care that can be related to diabetes. We hypothesise that this proportionality is determined by ubiquitous factors related to diabetes clinical manifestations and its care requirements that are likely to be broadly similar regardless of the setting. Therefore our adjusted 1.22 -fold higher estimate of hospital costs in DM patients suggests that we might expect to see a $22 \%$ increased cost associated with DM in other settings as well. 


\section{Conclusions}

Our study found increased duration and costs of hospitalisation in the very large proportion of our hospital inpatients who had DM. It suggests that DM contributes in an indirect but quantitatively very significant way to overall hospital costs in our setting. This adds to estimates of an overall $86 \%$ increase in health expenditure (from AUD 811 million to AUD 1,507 million) on diabetes in Australia between 2000-2001 and 2008-2009 ${ }^{2}$. Future research should aim to determine whether and to what extent system and/or patient factors are driving these differences within the hospital. This might identify modifiable factors, both patient and organisational, which would enable more cost effective healthcare delivery.

This article is protected by copyright. All rights reserved. 
1. Australian Institute of Health and Welfare (AlHW). Diabetes prevalence in Australia: detailed estimates for 2007-08. Diabetes Series no. 17. Cat. no. CVD 56. Canberra: AlHW, 2011.

2. Australian Institute of Health and Welfare (AlHW). Diabetes expenditure in Australia 2008-09. Cat. no. CVD 62. Canberra: AlHW, 2013.

3. Colagiuri S, Colagiuri R, Grainger D, Graham-Clarke P, Davey P, Fitzgerald P, et al. DiabCost Australia - assessing the burden of Type 2 diabetes in Australia. Diabetologia. 2002;45:A300-A300.

4. Bach LA, Ekinci EI, Engler D, Gilfillan C, Hamblin PS, Maclsaac RJ, et al. The high burden of inpatient diabetes mellitus: the Melbourne Public Hospitals Diabetes Inpatient Audit. Med J Aust. 2014;201(6):334-338.

5. The International Statistical Classification of Diseases and Related Health Problems (ICD-10-AM), 10th Revision, Australian Modification. Tabular List. 9th Edition, 1 July 2015. Published by the Hospital Pricing Authority (IHPA). 2015.

6. Charlson M, Szatrowski TP, Peterson J, Gold J. Validation of a combined comorbidity index. J Clin Epidemiol. 1994;47(11):1245-1251.

7. Charlson ME, Pompei P, Ales KL, MacKenzie CR. A new method of classifying prognostic comorbidity in longitudinal studies: development and validation. J Chronic Dis. 1987;40(5):373-383.

8. Kameshwar K, Karahalios A, Janus E, Karunajeewa H. False economies in homebased parenteral antibiotic treatment: a health-economic case study of management of lower-limb cellulitis in Australia. J Antimicrob Chemother. 2016;71(3):830-835.

9. World Health Organization. The International Statistical Classification of Diseases and Related Health Problems (ICD-10), 2010 Edition. 2010.

10. Deyo RA, Cherkin DC, Ciol MA. Adapting a clinical comorbidity index for use with ICD-9-CM administrative databases. J Clin Epidemiol. 1992;45(6):613-619.

11. Quan H, Sundararajan V, Halfon P, Fong A, Burnand B, Luthi JC, et al. Coding algorithms for defining comorbidities in ICD-9-CM and ICD-10 administrative data. Med Care. 2005;43(11):1130-1139.

12. Bassi A, Dodd S, Williamson P, Bodger K. Cost of illness of inflammatory bowel disease in the UK: a single centre retrospective study. Gut. 2004;53(10):1471-1478.

13. Dodd S, Bassi A, Bodger K, Williamson P. A comparison of multivariable regression models to analyse cost data. J Eval Clin Pract. 2006;12(1):76-86.

14. Moran JL, Solomon PJ, Peisach AR, Martin J. New models for old questions: generalized linear models for cost prediction. J Eval Clin Pract. 2007;13(3):381-389.

15. Efron B. Nonparametric Estimates of Standard Error - the Jackknife, the Bootstrap and Other Methods. Biometrika. 1981;68(3):589-599.

16. Stata Corporation. Stata statistical software: Release 13. College Station, Texas: Stata Corp LP; 2013.

17. Mata-Cases M, Casajuana M, Franch-Nadal J, Casellas A, Castell C, Vinagre I, et al. Direct medical costs attributable to type 2 diabetes mellitus: a population-based study in Catalonia, Spain. Eur J Health Econ. 2015.

18. Selby JV, Ray GT, Zhang D, Colby CJ. Excess costs of medical care for patients with diabetes in a managed care population. Diabetes Care. 1997;20(9):1396-1402.

19. Sortso C, Green A, Jensen PB, Emneus M. Societal costs of diabetes mellitus in Denmark. Diabet Med. 2015.

20. Ncube-Zulu T, Danckwerts M. Comparative hospitalization cost and length of stay between patients with and without diabetes in a large tertiary hospital in Johannesburg, South Africa. International Journal of Diabetes in Developing Countries 2013;34(3):156-162.

21. Olveira-Fuster G, Olvera-Marquez P, Carral-Sanlaureano F, Gonzalez-Romero S, Aguilar-Diosdado M, Soriguer-Escofet F. Excess hospitalizations, hospital days, and inpatient costs among people with diabetes in Andalusia, Spain. Diabetes Care. 2004;27(8):1904-1909.

22. Diabetes Australia. National Diabetes Service Scheme 2016 [cited 201616 June 2016]. Available from: http://www.aihw.gov.au/diabetes/index.cfm. 
23. Tancredi M, Rosengren A, Svensson AM, Kosiborod M, Pivodic A, Gudbjornsdottir S, et al. Excess Mortality among Persons with Type 2 Diabetes. N Engl J Med. 2015;373(18):1720-1732.

24. Nanayakkara N, Nguyen H, Churilov L, Kong A, Pang N, Hart GK, et al. Inpatient HbA1c testing: a prospective observational study. BMJ Open Diabetes Res Care. 2015;3(1):e000113.

25. Volk ML, Hernandez JC, Lok AS, Marrero JA. Modified Charlson comorbidity index for predicting survival after liver transplantation. Liver Transpl. 2007;13(11):15151520. 
Table 1: Characteristics of the 4,658 patients discharged from General Internal Medicine by presence or absence of diabetes mellitus: 1 July 2012 to 30 June 2013.

\begin{tabular}{lcc}
\hline Characteristics & $\begin{array}{c}\text { No diabetes } \\
\text { mellitus } \\
\text { Number (\%) or } \\
\text { median [lQR] }\end{array}$ & $\begin{array}{c}\text { Diabetes mellitus } \\
\text { Number (\%) or } \\
\text { median [IQR] }\end{array}$ \\
\hline Total & 3,139 & 1,519 \\
Sex $^{\dagger}$ & $1,415(45)$ & $770(51)$ \\
Males & $1,723(55)$ & $749(49)$ \\
Females & $76[58,85]$ & $77[68,83]$ \\
Age group (years) & $865(28)$ & $208(14)$ \\
$<=60$ & $1,073(34)$ & $781(51)$ \\
$60-80$ & $1,201(38)$ & $530(35)$ \\
$>80$ & & \\
English speaking & $668(21)$ & $539(36)$ \\
No & $2,471(79)$ & $980(65)$ \\
Yes & & \\
Spousal support & $1,729(55)$ & $712(47)$ \\
No & $1,410(45)$ & $807(53)$ \\
Yes & & \\
Ever smoked & $2,195(70)$ & $1,003(66)$ \\
No & $944(30)$ & $516(34)$ \\
Yes & $1[0,2]$ & $3[2,5]$ \\
Charlson Comorbidity Index ${ }^{\ddagger}$ & $1,557(50)$ & $0(0.0)$ \\
0 & $1,116(36)$ & $687(45)$ \\
$1-2$ & $466(15)$ & $832(55)$ \\
$>2$ & $1[0,2]$ & $1[0,3]$ \\
Modified Charlson Comorbidity Index & $1,557(50)$ & $542(36)$ \\
0 & $1,116(36)$ & $577(38)$ \\
$1-2$ & $466(15)$ & $400(26)$ \\
$>2$ &
\end{tabular}

Abbreviation: IQR $=$ Inter-quartile range; $25^{\text {th }}$ and $75^{\text {th }}$ percentiles

† 1 person with missing data for sex has been removed from subsequent analyses.

${ }^{\ddagger}$ ICD-10 codes were mapped to the 19 comorbidity classifications comprising the $\mathrm{CCI}^{6,7}$.

$\S$ Analogous to Volk et al ${ }^{25}$, Modified Charlson Comorbidity Index is derived by excluding diabetes mellitus from the score.

Note, column totals might not sum to $100 \%$ because of rounding 
Table 2: Association between diabetes mellitus and (i) individual clinical costs and (ii) length of stay from multivariable models ${ }^{\dagger}: 1$ July 2012 to 30 June 2013.

\begin{tabular}{|c|c|c|c|c|c|}
\hline \multirow[t]{2}{*}{ Variable } & \multirow[b]{2}{*}{$\mathrm{N}(\%)$} & \multicolumn{2}{|c|}{ Individual clinical costs ${ }^{\ddagger}$} & \multicolumn{2}{|l|}{ Length of stay ${ }^{\S}$} \\
\hline & & $\begin{array}{l}\text { Relative increase } \\
(95 \% \mathrm{Cl})\end{array}$ & P-value & Odds ratio $(95 \% \mathrm{Cl})$ & P-value \\
\hline \multicolumn{6}{|l|}{ Diabetes Mellitus } \\
\hline No & $3,138(67.4)$ & Ref & - & Ref & - \\
\hline Yes & $1,519(32.6)$ & $1.28(1.15,1.43)$ & $<0.001$ & $1.19(1.06,1.33)$ & 0.002 \\
\hline Uncomplicated ${ }^{\pi}$ & $548(11.8)$ & $0.81(0.69,0.94)$ & 0.007 & $0.76(0.65,0.89)$ & 0.001 \\
\hline Complicated & 971 (20.9) & $1.70(1.49,1.93)$ & $<0.001$ & $1.56(1.37,1.78)$ & $<0.001$ \\
\hline \multicolumn{6}{|l|}{ Sex } \\
\hline Males & $2,185(46.9)$ & Ref & - & Ref & - \\
\hline Females & $2,472(53.1)$ & $0.89(0.80,0.98)$ & 0.019 & $0.94(0.85,1.05)$ & 0.267 \\
\hline \multicolumn{6}{|l|}{ Age group (years) } \\
\hline$<=60$ & $1,072(23.0)$ & Ref & - & Ref & - \\
\hline $60-80$ & $1,854(39.8)$ & $1.54(1.35,1.76)$ & $<0.001$ & $1.46(1.27,1.68)$ & $<0.001$ \\
\hline$>80$ & $1,731(37.2)$ & $1.47(1.28,1.68)$ & $<0.001$ & $1.48(1.29,1.70)$ & $<0.001$ \\
\hline \multicolumn{6}{|l|}{ English speaking } \\
\hline No & $1,206(25.9)$ & Ref & - & Ref & - \\
\hline Yes & $3,451(74.1)$ & $0.85(0.76,0.96)$ & 0.007 & $0.89(0.79,1.00)$ & 0.049 \\
\hline \multicolumn{6}{|l|}{ Marital status } \\
\hline No & $2,440(52.4)$ & Ref & - & Ref & - \\
\hline Yes & 2,217 (47.6) & $0.94(0.85,1.04)$ & 0.220 & $0.90(0.81,1.00)$ & 0.044 \\
\hline \multicolumn{6}{|l|}{ Ever smoked } \\
\hline No & 3,197 (68.6) & Ref & - & Ref & - \\
\hline Yes & $1,460(31.4)$ & $1.53(1.37,1.71)$ & $<0.001$ & $1.56(1.39,1.75)$ & $<0.001$ \\
\hline \multicolumn{6}{|c|}{$\begin{array}{l}{ }^{\dagger} \text { Multivariable models have been adjusted for the covariates in the table (i.e. diabetes (yes/no), sex, age, English speaking, marital } \\
\text { status, and smoking). } \\
{ }^{\ddagger} \text { Estimated from a generalised linear model with a gamma error distribution and log-link function } \\
\S^{\S} \text { Estimated from an ordinal logistic regression analysis. Note, p-value from Brant test of parallel regression assumption is } 0.153 \text {, } \\
\text { suggesting no evidence against the null hypothesis that regression assumption of proportional odds has been violated. } \\
{ }^{\pi} \text { Uncomplicated: Diabetes mellitus without chronic complications }\end{array}$} \\
\hline
\end{tabular}

This article is protected by copyright. All rights reserved. 
Table 3: Associations from multivariable models ${ }^{\dagger}$ between diabetes mellitus and (i) total number of admissions ${ }^{\dagger}$ and (ii) mortality ${ }^{\ddagger}$ : 1 July 2012 to 30 June 2013.

\begin{tabular}{|c|c|c|c|c|c|}
\hline \multirow{2}{*}{ Variable } & \multirow[b]{2}{*}{$\mathrm{N}(\%)$} & \multicolumn{2}{|c|}{ Total number of admissions $^{\ddagger}$} & \multicolumn{2}{|c|}{ Mortality ${ }^{\S}$} \\
\hline & & Relative increase $(95 \% \mathrm{Cl})$ & $\mathrm{P}$-value & Odds ratio $(95 \% \mathrm{Cl})$ & P-value \\
\hline \multicolumn{6}{|l|}{ Diabetes Mellitus } \\
\hline No & $3,138(67.4)$ & Ref & - & Ref & - \\
\hline Yes & $1,519(32.6)$ & $1.07(1.01,1.13)$ & 0.022 & $1.00(0.79,1.28)$ & 0.974 \\
\hline Uncomplicated" & $548(11.8)$ & $0.91(0.84,0.99)$ & 0.032 & $0.55(0.35,0.85)$ & 0.008 \\
\hline Complicated ${ }^{*}$ & 971 (20.9) & $1.15(1.08,1.23)$ & $<0.001$ & $1.27(0.98,1.65)$ & 0.074 \\
\hline \multicolumn{6}{|l|}{ Sex } \\
\hline Males & $2,185(46.9)$ & Ref & - & Ref & - \\
\hline Females & $2,472(53.1)$ & $1.00(0.94,1.05)$ & 0.891 & $0.67(0.52,0.85)$ & 0.001 \\
\hline \multicolumn{6}{|l|}{ Age group (years) } \\
\hline$<=60$ & $1,072(23.0)$ & Ref & - & Ref & - \\
\hline $60-80$ & $1,854(39.8)$ & $1.11(1.03,1.19)$ & 0.005 & $3.94(2.37,6.56)$ & $<0.001$ \\
\hline$>80$ & $1,731(37.2)$ & $1.11(1.03,1.19)$ & 0.005 & $8.03(4.90,13.15)$ & $<0.001$ \\
\hline \multicolumn{6}{|l|}{ English speaking } \\
\hline No & $1,206(25.9)$ & Ref & - & Ref & - \\
\hline Yes & $3,451(74.1)$ & $0.91(0.85,0.96)$ & 0.001 & $0.99(0.77,1.27)$ & 0.940 \\
\hline \multicolumn{6}{|l|}{ Spousal support } \\
\hline No & $2,440(52.4)$ & Ref & - & Ref & - \\
\hline Yes & 2,217 (47.6) & $0.98(0.93,1.03)$ & 0.377 & $0.89(0.70,1.14)$ & 0.365 \\
\hline \multicolumn{6}{|l|}{ Ever smoked } \\
\hline No & 3,197 (68.6) & Ref & - & Ref & - \\
\hline Yes & $1,460(31.4)$ & $1.24(1.17,1.31)$ & $<0.001$ & $1.02(0.79,1.32)$ & 0.877 \\
\hline
\end{tabular}




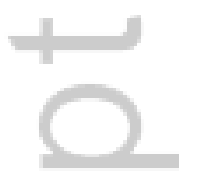

4 


\section{University Library}

\section{- M M N E R VA A gateway to Melbourne's research publications}

Minerva Access is the Institutional Repository of The University of Melbourne

Author/s:

Karahalios, A;Somarajah, G;Hamblin, PS;Karunajeewa, H;Janus, ED

Title:

Quantifying the hidden healthcare cost of diabetes mellitus in Australian hospital patients

Date:

2018-03-01

Citation:

Karahalios, A., Somarajah, G., Hamblin, P. S., Karunajeewa, H. \& Janus, E. D. (2018).

Quantifying the hidden healthcare cost of diabetes mellitus in Australian hospital patients.

INTERNAL MEDICINE JOURNAL, 48 (3), pp.286-292. https://doi.org/10.1111/imj.13685.

Persistent Link:

http://hdl.handle.net/11343/283436 